\title{
ANÁLISE DO CORDEL NO ENSINO DE GEOGRAFIA: VISÃO DA PERIFERIA E A VIOLÊNCIA URBANA
}

\section{CORDEL ANALYSIS IN TEACHING GEOGRAPHY: VISION OF THE PERIPHERY AND URBAN VIOLENCE}

\section{ANÁLISIS DEL CORDEL EN LA ENSEÑANZA DE LA GEOGRAFÍA: VISIÓN DE LA PERIFERIA Y VIOLENCIA URBANA}

Julia Gabriela Lessa de Queiroz ${ }^{1}$ Universidade do Estado do Rio de Janeiro, Rio de Janeiro, Brasil

Kelly Barradas Moreno ${ }^{2}$ Universidade do Estado do Rio de Janeiro, Rio de Janeiro, Brasil

Leandro Vieira Cardoso da Silva ${ }^{3}$

Universidade do Estado do Rio de Janeiro, Rio de Janeiro, Brasil

Resumo: O artigo tem como propósito compreender as dinâmicas que constituem a periferia e a violência construída a partir de oficina de elaboração de cordéis numa turma de $7^{\circ}$ ano no CIEP 439 - Luiz Gonzaga Júnior, Luiz Caçador, SG-RJ. Esta dinâmica foi realizada a partir do Projeto de Extensão de Oficinas Escolares de Geografia, a qual é desenvolvida com a temática Geografia, Literatura e Artes. Como resultado, percebemos que a grande maioria dos Cordéis relatara diferentes tipos de violência sofridas no local onde vivem, e com isso, nos motivou a aprofundar no tema para entender este processo.

Palavras-chave: Cordel; Periferia; Violência.

Abstract: This article its purpose is to understand the dynamics that constitute the periphery and the violence built from a cordel workshop in a 7th grade class at CIEP 439 - Luiz Gonzaga Júnior, Luiz Caçador, SG-RJ. This dynamic was realized from the Project Extension of School Workshops of Geography, which is developed with the theme Geography, Literature and Arts. As a result, we realized that most of the printed booklets named cordel had reported different types of violence suffered from the place where they live, and with this, the work motivated us to delve into the theme to understand the process.

Keywords: Cordel; Periphery; Violence.

\footnotetext{
${ }^{1}$ Graduanda em Geografia pela Universidade do Estado do Rio de Janeiro, E-mail: julialedq@ gmail.com ${ }^{2}$ Graduanda em Geografia pela Universidade do Estado do Rio de Janeiro, E-mail: kellybarradasmoreno@gmail.com

${ }^{3}$ Graduando em Geografia pela Universidade do Estado do Rio de Janeiro, E-mail: julialedq@ gmail.com leandrovieirac97@gmail.com
} 
Julia Gabriela Lessa de Queiroz

Kelly Barradas Moreno

Leandro Vieira Cardoso da Silva
Geografia, Literatura e Arte, v.2, n.2, p. 15-30, jul./dez.2020

DOI: 10.11606/issn.2594-9632.geoliterart.2020.167885

Resumen: El propósito de este artículo es comprender la dinámica que constituye la periferia y la violencia construida a partir de un taller de fabricación de cordel en una clase de séptimo grado en CIEP 439 - Luiz Gonzaga Júnior, Luiz Caçador, SG - RJ. Esta dinámica se realizó a partir del Proyecto de Extensión de Talleres Escolares de Geografía, que se desarrolla con el tema Geografía, Literatura y Artes. Como resultado, nos dimos cuenta de que la gran mayoría de los cordeles reportaron diferentes tipos de violencia sufrida en el lugar donde viven, y con eso, nos motivó a profundizar en el tema para comprender este proceso.

Palabras clave: Cordel; Periferia; Violencia.

\section{INTRODUÇÃO}

O ensino da Geografia está relacionado com a busca pela compreensão de diferentes formas de interpretação e análise do espaço geográfico e seus conceitos. Desta forma, podemos considerar que o espaço é constituído de fenômenos naturais, como também sociais, porque ele sofre constantemente transformações devido às necessidades dos contextos nos quais as sociedades vivenciam ao longo do tempo.

Para tanto, as diversas práticas metodológicas dos professores possibilitam formas de leitura espacial para além do uso tradicional do livro didático, buscando novas práticas pedagógicas de mediar o processo de aprendizagem, além de estabelecer um pensamento crítico acerca da leitura de mundo do aluno.

Essas práticas estabelecem não só metodologias como também as linguagens que são meios de desenvolver conceitos e conteúdos de maneira lúdica para os estudantes, uma vez que contribuem para articular formas de aprendizagem. Sendo assim, este texto traz a Literatura como uma linguagem para pensar e ensinar Geografia a partir das representações que esta mobiliza na construção do conhecimento geográfico.

O uso da literatura, especificamente da Literatura de Cordel, é uma linguagem que pode ser utilizada para trabalhar com os espaços vivenciados pelos estudantes, como uma forma de manifestação do seu entendimento experienciado. Por que o trabalho com o Cordel para ensinar geografia? Porque o Cordel pode possibilitar a construção da leitura por meio da realidade dos estudantes por meio de conceitos e conteúdos que trabalhem com as escalas de análise do global ao local. Segundo Barros e Barbosa (2008, p.7), “desenvolver, no aluno, vínculos com os costumes da sua 'gente', de sua 'terra' é reorientá-lo para perspectivas futuras em relação ao conhecimento". 
Julia Gabriela Lessa de Queiroz

Kelly Barradas Moreno

Leandro Vieira Cardoso da Silva
Geografia, Literatura e Arte, v.2, n.2, p. 15-30, jul./dez.2020

DOI: 10.11606/issn.2594-9632.geoliterart.2020.167885

Como podemos trabalhar com a literatura Cordel de uma maneira que dialogue a partir de uma discussão pensada pelos estudantes? Podemos fazer por meio de oficinas pedagógicas que buscam promover a construção do conhecimento pela mediação entre teoria e prática. Desta maneira, ao trabalhá-las desenvolvemos uma relação na qual eles precisam interagir e construir, em conjunto com os professores.

O presente artigo tem como objetivo compreender as dinâmicas que constituem a periferia e a violência ali presente, a partir de oficina de elaboração de cordéis numa turma de $7^{\circ}$ ano no CIEP 439 - Luiz Gonzaga Júnior, Luiz Caçador, SG-RJ, realizado no dia 25/10/2018, como uma atividade extracurricular, com duração de duas horas. Esta dinâmica foi realizada no $3^{\circ}$ período, a partir do Projeto de Extensão de Oficinas Escolares de Geografia durante a disciplina de Metodologias e Práticas Pedagógicas da Geografia, a qual é desenvolvida em diferentes escolas com a temática: Geografia, Literatura e Artes.

A proposta das oficinas na escola é promover aos estudantes do $3^{\circ}$ período a oportunidade de experimentar uma didática por meio da qual possam desenvolver e articular conteúdos geográficos. Para tanto, durante as aulas, buscamos planejar as etapas da organização da oficina, a partir da escolha do tema, dos objetivos, apresentação, justificativa, conteúdos, procedimentos metodológicos, material e referências bibliográficas.

Quando foi proposta a oficina Literatura de Cordel a ideia inicial era trabalhar com a linguagem, a origem e a história do Cordel, e articulado com um tema que fosse importante para os estudantes. Algumas premissas foram estabelecidas, como por exemplo, a necessidade de usar conceitos essenciais para a geografia: território, lugar, paisagem e região.

Durante a oficina o tema mais debatido entre eles que apontou a necessidade de discussão e reflexão foi a violência no bairro. Desta forma, o artigo que segue relatará como os estudantes, por meio de suas experiências com a violência na periferia, construíram os cordéis.

Por meio dessa atividade, os estudantes além de trabalharem o conceito da Literatura de Cordel, tiveram a possibilidade de reconhecer as diferentes realidades vivenciadas pelos seus colegas, além de entenderem mais sobre a dinâmica periférica, principalmente a do município de São Gonçalo, localizado na Região Metropolitana do Rio de Janeiro, onde foi realizada a oficina. 
Julia Gabriela Lessa de Queiroz

Kelly Barradas Moreno

Leandro Vieira Cardoso da Silva
Geografia, Literatura e Arte, v.2, n.2, p. 15-30, jul./dez.2020

DOI: 10.11606/issn.2594-9632.geoliterart.2020.167885

O principal fator apresentado neste texto é observar que a atividade acabou trazendo o cordel como o meio de entender a dinâmica da periferia, e por consequência, a violência presente em seus bairros.

Neste artigo, iremos discutir a relevância da literatura para o ensino da Geografia e a importância de outras metodologias, no que se refere à produção da cognição dos alunos, por meio da elaboração de recursos didáticos e sobre os resultados da atividade proposta: a conhecer a formação da periferia de São Gonçalo e como a violência gera impacto no/na discente.

\section{LITERATURA DE CORDEL E ENSINO DA GEOGRAFIA}

O ensino da Geografia nas escolas tem como objetivo permitir que os educandos tenham acesso aos conhecimentos sobre o espaço geográfico por meio dos principais conceitos da disciplina. Esses conceitos também nos auxiliam a compreender melhor a dinâmica do espaço vivido por meio de suas experiências. Nas palavras de Ruy Moreira (2007, p. 8), a idealização da Geografia pode ser apresentada como "uma forma de representação que vê e organiza o mundo através do conceito, restringindo a relação entre imagem e a fala a esse nível de representação.” No entanto, também são necessários novos métodos pedagógicos com capacidade de interdisciplinaridade para ampliar ainda mais a construção do pensamento de espacialidade.

Por meio da Geografia, também é possível permitir que os educandos identifiquem questões do seu próprio espaço através das categorias geográficas, como reforça Helena Callai (2003):

O estudo de geografia insere-se neste âmbito, na perspectiva de dar conta de como fazer a leitura de mundo, incorporando o estudo do território como fundamental para que se possa entender as relações que ocorrem entre os homens, estruturadas em um determinado tempo e espaço. O período das séries iniciais é o de construir os conceitos básicos da área, e que são básicos para a vida. (CALLAI, 2003, p. 77):

A leitura do mundo e o cotidiano do aluno no espaço vivido se dá a partir da compreensão dos conceitos, para tanto, é necessário que as/os docentes trabalhem por meio de diferentes linguagens e materiais didáticos para desenvolver forma de 
Julia Gabriela Lessa de Queiroz

Kelly Barradas Moreno

Leandro Vieira Cardoso da Silva
Geografia, Literatura e Arte, v.2, n.2, p. 15-30, jul./dez.2020

DOI: 10.11606/issn.2594-9632.geoliterart.2020.167885

aprendizagem que traga algo novo e que desperte o interesse do discente para que o conteúdo seja mediado de maneira fluída. Desse modo, surge como inspiração um dos recursos a serem utilizados na oficina, a Literatura de Cordel, um gênero literário, que pode ser definido como expressão popular da cultura brasileira, escrita de uma maneira rimada ou em forma de poesia para relatar diferentes temáticas. O Cordel chegou ao Brasil com os portugueses no século XVIII, essa manifestação cultural se popularizou por contar histórias de maneira clara, simples e rimada. Ao mesmo tempo que informa, o Cordel entretém o leitor.

A Literatura de Cordel, como uma linguagem na sala de aula, aumenta a possibilidade de fazer com que o aluno observe um determinado tema de forma mais objetiva e dinâmica. Além de aguçar seu senso crítico e sensível, fazendo com que este aluno identifique questões do seu próprio espaço, podendo problematizar diferentes assuntos acerca da atualidade, e assim, despertar um maior interesse na área da Geografia e intensificar a valorização desta disciplina para que tenha sua visibilidade em destaque no processo de ensino-aprendizagem.

Além disso, o uso do cordel, como uma linguagem no ensino da geografia possibilita cativar a atenção do/da discente, tornando a disciplina mais interessante para fazer com que ele aprenda de maneira interativa e facilite sua compreensão em analisar as problemáticas sociais e sua inserção na sociedade, como pode ser retratado através da seguinte citação:

Um procedimento metodológico que oriente o trabalho com o cordel terá que favorecer o diálogo com a cultura da qual ele emana e, ao mesmo tempo, uma experiência entre professor e aluno, e os demais participantes do processo [...]. Deve-se, portanto, recolher dos próprios alunos relatos de suas vivências, experiências deles conhecidas, e, ao mesmo tempo, das obras - os folhetos - e penetrar nas questões que lá estão representadas (MARINHO; PINHEIRO, 2012, p.126).

Dessa maneira, trabalhar interdisciplinarmente Geografia e Literatura de Cordel pode ser uma forma de contribuir para que o aluno entenda outros modos de apropriação e ampliação do debate sobre o espaço vivido, bem como outras escalas de análise. Neste trabalho, a questão da violência na periferia é algo que demarca a construção do conhecimento geográfico. 
Julia Gabriela Lessa de Queiroz

Kelly Barradas Moreno

Leandro Vieira Cardoso da Silva
Geografia, Literatura e Arte, v.2, n.2, p. 15-30, jul./dez.2020

DOI: 10.11606/issn.2594-9632.geoliterart.2020.167885

\section{PENSAR A ESPACIALIDADE DA PERIFERIA DE SÃO GONÇALO E O ENSINO DA GEOGRAFIA}

A periferia é o local que está nos arredores de uma região sendo dependente dos serviços prestados nos grandes centros urbanos. Ao trazer o conceito de periferia visando à cidade de São Gonçalo, devemos analisar a formação de ocupação da cidade. Segundo Rosa (2010), a ocupação do município ocorreu com a migração da mão de obra que não tinha condições de se manter nos grandes centros urbanos fazendo do local uma cidade dormitório, usada apenas para descanso já que os grandes comércios e áreas de lazer estão localizados nos grandes centros como o caso do município de Niterói.

O que soa estranho é a veemência da repetição por parte dos governos urbanos, da ideia de que os problemas de São Gonçalo vinham do processo de especialização da metrópole. Era a noção de que os espaços encontravam-se rigidamente articulados através da existência de uma hierarquia urbana. A metrópole seria responsável pela provisão de serviços de maior valor agregado e à periferia, caberia o papel de cidade - dormitório que abrigava o reservatório de mão-de-obra de trabalhadores com baixa qualificação (ROSA, 2010, p. 24).

Também é possível caracterizá-la como periferia, locais com, precarização dos serviços. Em São Gonçalo determinadas áreas sofrem com falta de saneamento básico, falta de coleta de lixo, esgoto a céu aberto, acarretando então, doenças para a população. Além disso, o município também sofre com a falta de planejamento urbano, levando em consideração a ocorrência de enchentes em dias de chuvas fortes e intensas.

A periferia é compreendida no imaginário comum como um meio marginalizado, violento. No livro Solos Culturais, organizado por Jorge Luiz Barbosa e Caio Gonçalves Dias (2013), os autores Jailson de Souza e Silva e Jorge Luiz Barbosa retratam a favela como:

As favelas sempre foram consideradas, nos discursos hegemônicos, como territórios da ausência da civilidade e da urbanidade. A obediência ao senso comum fez com que o Instituto Brasileiro de Geografia e Estatística (IBGE) definisse, desde o Censo de 1990, as favelas como aglomerados subnormais, termo que ratifica o conteúdo conceitual historicamente utilizado. (SILVA; BARBOSA, 2013, p. 29) 
Julia Gabriela Lessa de Queiroz

Kelly Barradas Moreno

Leandro Vieira Cardoso da Silva
Geografia, Literatura e Arte, v.2, n.2, p. 15-30, jul./dez.2020

DOI: 10.11606/issn.2594-9632.geoliterart.2020.167885

Para entender a formação periférica é necessário compreender o processo que concebeu a urbanização no Brasil. O desenvolvimento urbano é iniciado na década de 1950, enquanto moradores de áreas rurais migram para as cidades gerando nelas um forte impacto. Esse êxodo rural gerou uma grande procura de empregos e de moradia nas cidades, acarretando um exército de mão de obra que pela falta de qualificação e para se manter, aceitavam salários mais baixos. Pelo mesmo motivo, ocupavam as margens desses locais, pois precisavam estar próximos do ofício.

Mediante esse fenômeno de migração deu-se o início da periferia. Nesses locais, pessoas com baixo poder de compra começaram a ocupar terrenos com valores mais acessíveis ou loteamentos clandestinos. Essas moradias, por estarem mais distantes da metrópole, carecem de investimentos do governo e por isso falta o básico, como saúde, educação, saneamento, cultura e áreas de lazer, deixando os habitantes dependente da dinâmica central, consolidando estruturas de privações de bens comuns que ficam reduzidos a regiões mais desenvolvidas e abastadas.

$\mathrm{Na}$ percepção de cidade como um espaço de convivência e de relações econômicas, comerciais, habitacionais e lazer, nota-se que devido ao seu crescimento acelerado, o número de violência, desemprego e desigualdade social consequentemente também cresce. A partir da urbanização, espaços segregacionistas sociais e econômicos são criados, como por exemplo bairros de classe alta, média e baixa. A segregação urbana está intimamente relacionada com a luta de classes e formas de resistência, em que a população mais pobre tende a habitar áreas periféricas e menos acessíveis aos centros urbanos. Geralmente, esses espaços segregados apresentam menor infraestrutura como saneamento básico, acesso a serviços e pavimentação.

Para engajar as/os estudantes na discussão sobre essas problemáticas e sobre seu papel na sociedade, é necessário abordar a visão e o entendimento de mundo de cada um/uma deles/delas, pois conforme diz Lana Cavalcanti (2002, p. 11):

O pensar geográfico contribui para a contextualização do próprio aluno como cidadão do mundo, ao contextualizar espacialmente os fenômenos ao conhecer o mundo em que vive desde a escala local à regional, nacional e mundial. O conhecimento geográfico é, pois indispensável à formação de indivíduos participantes da vida social, à medida que propicia o entendimento do espaço geográfico e do papel desse espaço nas práticas sociais. 
Julia Gabriela Lessa de Queiroz

Kelly Barradas Moreno

Leandro Vieira Cardoso da Silva
Geografia, Literatura e Arte, v.2, n.2, p. 15-30, jul./dez.2020

DOI: 10.11606/issn.2594-9632.geoliterart.2020.167885

Cabe salientar também que o processo de segregação socioespacial se iniciou devido à discrepância representada por uma espécie de precipício entre uma realidade e outra, no que diz respeito ao acesso ao direito à cidadania. É possível perceber isso com mais clareza nos grandes centros urbanos, nos quais, esse contraste está totalmente relacionado com a desigualdade social, uma vez que os bairros habitados por moradores ricos possuem um maior suporte quanto à habitação, saúde, segurança, trabalho, justiça e educação. Já os bairros habitados por moradores pobres detêm essa assistência básica de maneira escassa ou quase inexistente.

Pode-se analisar as diferentes realidades vividas através da perspectiva das classes sociais, visto que uma classe possui dominação sobre a outra, por interesses tanto políticos quanto econômicos, que contribuem para o crescimento da desigualdade, na medida que um pequeno grupo desfruta de privilégios enquanto o outro encontra-se desamparado. Por isso, deve ser levado em consideração a maneira que uma sociedade está organizada e como o desencadeamento da restrição de uma boa qualidade de vida afeta não só o direito à cidadania como já foi mencionado, como também a oferta de oportunidades para a população mais fragilizada.

Por intermédio das práticas pedagógicas dos professores, torna-se extremamente significativa a colaboração de uma formação escolar crítica, capaz de vincular a atuação da ideia do exercício da cidadania e configuração da conscientização de classes, como sugerido pela autora Cavalcanti (2006, p. 32):

Para que os alunos entendam os espaços de sua vida cotidiana, que se tornaram extremamente complexos, é necessário que aprendam a olhar, ao mesmo tempo, para um contexto mais amplo e global, do qual todos fazem parte, e para elementos que caracterizam e distinguem seu contexto local.

Com base nos dados retirados do Instituto Brasileiro de Geografia e Estatística (IBGE) em 2017 (figura 1), um dos principais indicadores que colabora para as diferenças socioeconômicas está conectado com o grau de escolaridade da população. Constata-se que essa desigualdade afeta principalmente a massa excluída socialmente, pois não recebe as mesmas condições necessárias na educação que garantam futuramente um equilíbrio na distribuição de renda. 
Julia Gabriela Lessa de Queiroz

Kelly Barradas Moreno

Leandro Vieira Cardoso da Silva
Geografia, Literatura e Arte, v.2, n.2, p. 15-30, jul./dez.2020

DOI: 10.11606/issn.2594-9632.geoliterart.2020.167885

Figura 1 - Rendimento médio mensal

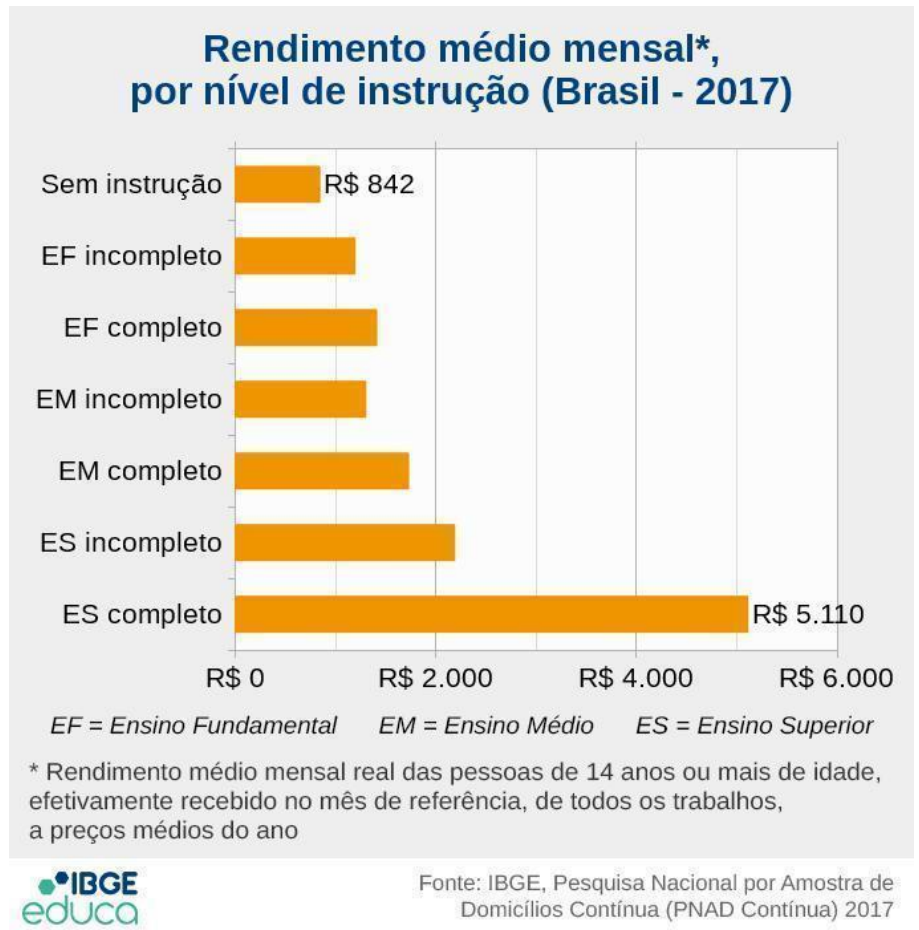

Fonte: IBGE, Pesquisa Nacional por Amostra de Domicílios Contínua (PNAD Contínua) 2017.

Por meio do fato mencionado acima, é perceptível que a estrutura social onde a periferia sofre com o descaso do Estado, muitos moradores precisam se desdobrar entre fugir da violência local, estudo e trabalho. Pensando nisso, é importante analisar que muitos não conseguem e não podem sustentar essa rotina, tendo em vista que o trabalho consome a maior parte do tempo, e a assistência dada pelo governo não supre as necessidades dos residentes. Como resultado, grande parte acaba optando pelo ofício e acabam virando um exército de mão de obra, de modo que a educação acaba sendo deixada de lado, colaborando assim, para a persistência dessa disparidade.

No cordel produzido pelo aluno Joan, por exemplo, é observado seu descontentamento sobre o modo como as pessoas lidam com a política, efetuando trocas de votos e desprezando a importância do seu direito. Assim, a periferia continua sendo esquecida pelo governo, precarizada em segurança pública, saneamento básico e principalmente em educação.

Minha favela, um lugar que eu quero melhorar, mas não vou conseguir, por que o "Brasil" NÃO SAI DO LUGAR 
Julia Gabriela Lessa de Queiroz

Kelly Barradas Moreno

Leandro Vieira Cardoso da Silva
Geografia, Literatura e Arte, v.2, n.2, p. 15-30, jul./dez.2020

DOI: 10.11606/issn.2594-9632.geoliterart.2020.167885

Um lugar bonito e um pouco agressivo

Lá até queria tenta

Mas como se o povo continua fu**** desculpa o palavrão

Mais eu tive que falar como

VAI MUDAR SE O POVO NÃO SABE

VOTAR

Um povo que se troca por comida, cervejas

como vamos mudar, se o

povo se troca em VÃO (Cordel do aluno Joan Villela)

O Cordel como manifestação cultural, rica de experiências, parte do mesmo princípio do ensino da Geografia: a realidade do aluno. Essa realidade é estabelecida como um produto social, gerado a partir das relações que acontecem, nesse caso, na periferia, como dialoga Cavalcanti (2006, p. 30-31):

\begin{abstract}
A Geografia, nesse contexto, tem se desenvolvido, tornando-se uma ciência mais plural. Por um lado, ela reafirma seu foco de análise, que é o espaço, mas, por outro, torna-se mais consciente de que esta é uma dimensão da realidade, e não a própria realidade, complexa e interdisciplinar por si mesma. O espaço como objeto de análise geográfica não é aquele da experiência empírica, não é um objeto espacial em si mesmo, mas sim uma abstração, uma construção teórica; o espaço geográfico é concebido, construído intelectualmente como um produto social e histórico, que se constitui em ferramenta que permite analisar a realidade em sua dimensão material e em sua representação.
\end{abstract}

A periferia é a materialização de dinâmicas e práticas sociais, que são constituídas de um sentimento de pertencimento, como foi visto nos cordéis, como por exemplo o uso do pronome possessivo "minha" utilizado pelo aluno Joan Villela. O ensino da Geografia é presente no uso do cordel para trazer essa realidade do aluno para a prática ensino/aprendizado.

\title{
4. VIOLÊNCIA NA PERIFERIA: PENSANDO AS RELAÇÕES COM A CIDADE DE SÃO GONÇALO E OS ESTUDANTES DA ESCOLA BÁSICA
}

Sabe-se que São Gonçalo, além de ser considerada uma cidade periférica, está marcada por muitos conjuntos de habitações populares, em sua maioria tomada pelo poder do tráfico tendo um grande peso social, pois são lugares caracterizados pela violência de ambas partes, a do crime e de intervenção do Estado. Os moradores que convivem nesses 
Julia Gabriela Lessa de Queiroz

Kelly Barradas Moreno

Leandro Vieira Cardoso da Silva
Geografia, Literatura e Arte, v.2, n.2, p. 15-30, jul./dez.2020

DOI: 10.11606/issn.2594-9632.geoliterart.2020.167885

ambientes acabam lidando com os momentos de tensão entre confrontos de facções criminosas e os confrontos policiais. Outro fator importante, é que grande parte dos moradores dessas regiões não possuem poder aquisitivo elevado, e muitos estudantes conciliam concomitantemente escola e trabalho para poder auxiliar com a renda domiciliar.

Na oficina Literatura de Cordel realizada com os alunos e alunas, foi ensinado sobre o que era o Cordel e os fundamentos básicos da Geografia, com ênfase no conceito de paisagem e lugar. Logo após a explicação, os estudantes foram instruídos a produzirem seu próprio cordel tendo como base o tema "O que espero do meu lugar no futuro".

Muitos cordéis escritos pelos alunos e alunas retratam uma realidade sobre as violências vividas e o descaso do governo em meio a essa demanda escassa de segurança pública e investimentos para sanar as necessidades de lazer e cultura, como pode ser observado no seguinte cordel:

O futuro que eu quero...

É com menos violência, melhorias nas escolas. Um país com menos tiros e menos assaltos etc...

Aonde eu moro não é um lugar muito bom, por culpa dos bandidos. É o que Brasil eu quero é com menos crime e menos mortes etc...

Quero melhorias em escolas públicas. (Cordel da aluna Tatiane)

Nos últimos anos, a violência tem crescido de forma significante em decorrência da ausência de políticas públicas nas localidades mais carentes, visto que o crime organizado influencia cada vez mais para o aumento da criminalidade através da ascensão do tráfico de drogas. A partir disso, esses espaços se tornaram mais vulneráveis ao controle territorial por grupos que atuam em práticas ilegais, e estabelecem o poder por meio da intimidação. Porém, muitas vezes, estes realizam o papel das autoridades, atendendo as necessidades básicas da população que vive nas áreas de risco, fortalecendo e expandindo seu domínio para outros locais. Marcos Rolim, em sua tese diz que: 
Julia Gabriela Lessa de Queiroz

Kelly Barradas Moreno

Leandro Vieira Cardoso da Silva
Geografia, Literatura e Arte, v.2, n.2, p. 15-30, jul./dez.2020

DOI: 10.11606/issn.2594-9632.geoliterart.2020.167885

Para Sutherland, deve-se partir da constatação de que os comportamentos disruptivos são assimilados a partir da interação com pessoas envolvidas com o crime e a violência. Neste processo, as pessoas teriam contato não apenas com os valores que amparam as ações transgressoras, mas também com as técnicas delituosas e com as racionalizações típicas empregadas pelos autores e que lhes são fundamentais para "suportar" a consciência de terem rompido as normas legais. (ROLIM, 2014, p.47)

Ainda convém lembrar que a educação possui extrema importância para auxiliar no combate a violência, pois ela tem como principal objetivo oferecer conhecimento aos alunos e permitir que o professor faça a mediação do aprimoramento desses conhecimentos, a fim de colaborar para a formação de uma sociedade mais justa. No entanto, os impactos causados devido ao contraste estabelecido no modo de vida das pessoas, a falta de investimentos e o descaso do governo também contribuem para a desvalorização da educação e para a evasão escolar, em que boa parte dos jovens abandona os estudos para começar trabalhar e ajudar no sustento da família ou são influenciados para entrar no mundo do crime.

Não se pode esquecer que existe uma grande resistência diante das dificuldades que as escolas possuem, especificamente as públicas, para poder mediar os conteúdos necessários. A falta de recursos precariza cada vez mais o ensino e impede não só um melhor desenvolvimento dos alunos e alunas, mas também a compreensão de sua realidade geográfica, visto que são influenciadas por uma reorganização tanto política quanto econômica que afetam no modo de vida de determinada população.

O que é expresso no cordel abaixo mostra-nos a indignação do aluno diante da sua realidade. Nesse sentido, as problemáticas tratadas revelam de fato os aspectos da desigualdade que resultam na propagação da violência e dos conflitos sociais que acentuam, cada vez mais, a criminalidade nas cidades e que precisam ser contidas através da educação de qualidade.

O meu lugar, é te uma paisagem melhor, Com tiroteio a vida fica pior, o nosso país precisa melhorar. O meu lugar é se jogador de futebol, fazer muitos gols e da muitos lençols, eu tenho fé que vou chegar lá.

O meu lugar, é ter um bairro com felicidade e união, e o ladrão ter mais compaixão, 
Julia Gabriela Lessa de Queiroz

Kelly Barradas Moreno

Leandro Vieira Cardoso da Silva
Geografia, Literatura e Arte, v.2, n.2, p. 15-30, jul./dez.2020

DOI: 10.11606/issn.2594-9632.geoliterart.2020.167885

para com essa matança.

O meu lugar, ficar ne um campo

soltando uma pipa, ter um lugar com muita alegria,

madurerá. FIM (Cordel do aluno Matheus Gabriel)

No cenário atual, pode ser observado que existe uma perspectiva de estereótipos e estigmas presentes na sociedade para caracterizar os indivíduos que moram nas regiões marginalizadas, como 'delinquentes' ou 'bandidos', com o objetivo de inferiorizar o sujeito e defini-lo como criminoso, no qual ele é discriminado por sua aparência, pela sua maneira de andar, falar e vestir. Além disso, o preconceito racial também é um reflexo dessa marginalização quando se fala na desproporção de oportunidades oferecidas aos negros em relação aos brancos.

Esse poder de repressão é denominado pelo filósofo francês Michel Foucault (2005) como biopoder, o uso do aparato repressor estatal para subjugação de corpos e da própria população. Existem grupos de importância que é preciso 'fazer viver' ou continuar vivendo, mesmo que seja necessário que esse grupo faça com que outros sejam passíveis do 'deixar morrer'. A morte, então, se instrumentaliza como uma manutenção do poder, usando o nazismo como exemplo. Vimos que para a ascensão e permanência da vida dos alemães arianos, era necessário que minorias fossem mortas, como os judeus e os ciganos. O poder que rege o biopoder é o preconceito, no caso do nazismo, o racismo. No texto Em defesa da sociedade, Foucault (2005) dialoga sobre a funcionalidade do biopoder:

\begin{abstract}
Portanto, relação não militar, guerreira ou política, mas relação biológica. E, se esse mecanismo pode atuar é porque os inimigos que se trata de suprimir não são os adversários no sentido político do termo; são os perigos, externos ou internos, em relação à população e para a população. Em outras palavras, tirar a vida, o imperativo da morte, só é admissível, no sistema de biopoder, se tende não à vitória sobre os adversários políticos, mas à eliminação do perigo biológico e ao fortalecimento, diretamente ligado a essa eliminação, da própria espécie ou da raça. A raça, o racismo, e a condição de aceitabilidade de tirar a vida numa sociedade de normalização. (FOUCAULT, 2005, p. 305-306)
\end{abstract}

Então, se é o poder soberano que governa o direito sobre a vida e a morte, é necessário passar pelo racismo para poder exercer esse direito sobre a morte. "Quando for preciso matar pessoas, matar populações, matar civilizações, como se poderá fazê-lo, se se funcionar no modo do biopoder? Através dos temas do evolucionismo, mediante um racismo" (FOUCAULT, 2005, p. 307). 
Julia Gabriela Lessa de Queiroz

Kelly Barradas Moreno

Leandro Vieira Cardoso da Silva
Geografia, Literatura e Arte, v.2, n.2, p. 15-30, jul./dez.2020

DOI: 10.11606/issn.2594-9632.geoliterart.2020.167885

\section{CONCLUSÃO PARA EXPERIMENTOS.}

Ao final da confecção dos cordéis os alunos poderiam apresentar o que desenvolveram. Quando voltamos e reunimos os resultados, percebemos que a grande maioria dos cordéis relataram o convívio com violência cotidiana. Por meios dos cordéis, meninos e meninas, falaram de brigas e tiroteios e as meninas falaram de abusos físicos e psicológicos, em um caso específico uma aluna manifestou a vontade de cometer suicídio, o que nos incentivou a trabalhar no tema para entendermos tanto essa dinâmica do espaço geográfico e como o professor deve se portar diante dessa situação.

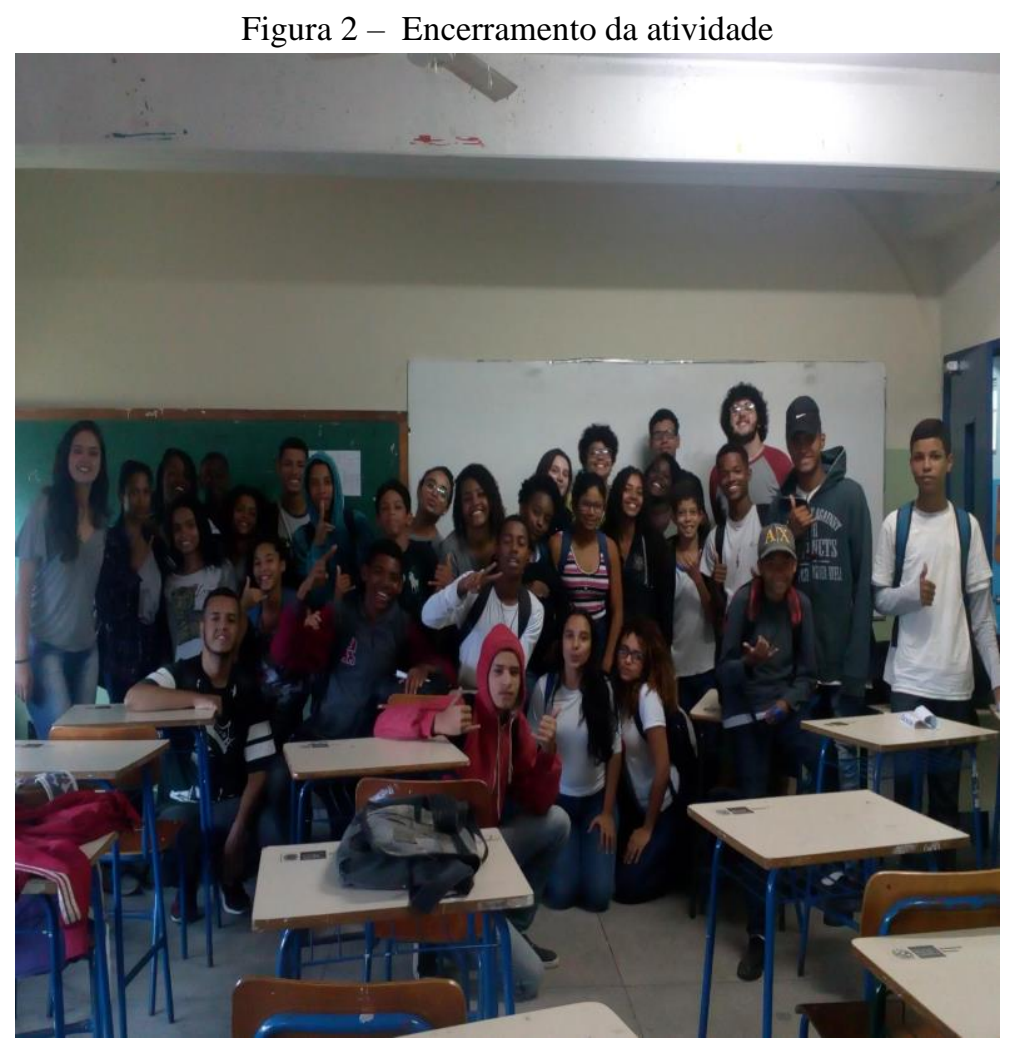

Fonte: arquivo de Ana Cláudia Sacramento (2018)

A proposta metodológica aplicada incentivou não só o processo de desenvolvimento desse artigo, como também o estabelecimento do pensamento para nós graduandos e para os alunos do CIEP 439, sobre as problemáticas inseridas na sociedade e a importância que a Geografia tem em compreender os desafios encontrados diante da concepção do mundo atual e dos impactos causados pela desigualdade social, de modo 
Julia Gabriela Lessa de Queiroz

Kelly Barradas Moreno

Leandro Vieira Cardoso da Silva
Geografia, Literatura e Arte, v.2, n.2, p. 15-30, jul./dez.2020

DOI: 10.11606/issn.2594-9632.geoliterart.2020.167885

que pudesse atrair a atenção dos estudantes, tornando a oficina mais interessante com o uso do cordel como recurso.

O resultado da atividade foi formidável, os alunos estavam dispostos a realizar a tarefa, e expressaram o que foi proposto através da arte do Cordel trabalhando a Geografia e o cotidiano vivido, proporcionando a construção de conhecimento não só da disciplina em si, mas também de outra manifestação literária que é tão presente no Nordeste, porém, pouco trabalhada nas escolas de São Gonçalo, somado à possibilidade de o discente externar sua concepção de mundo, a partir dessa estratégia pedagógica.

\section{REFERÊNCIAS}

BARROS, Dilsom; BARBOSA, Vilma de Lurdes Barbosa. A literatura de cordel no ensino de geografia. X Encontro de Extensão Universitária. Paraíba: UFPB, 2008.

CALLAI, Helena Copetti. O estudo do município ou a Geografia nas séries iniciais. In: CASTROGIOVANNI, Antonio Carlos, et all. Geografia em sala de aula: práticas e reflexões. $4^{\mathrm{a}}$ ed. Porto Alegre: UFRGS, 2003.

CAVALCANTI, Lana de Souza. Geografia e prática de ensino. Goiânia: Alternativa. Campinas, SP: Papirus, 2002.

CAVALCANTI, Lana de Souza. Bases teórico-metodológicas da Geografia: uma referência para a formação e a prática de ensino. In: CAVALCANTI, L.S. (Org). Formação de professores: concepções e práticas em geografia Goiania: E.Vieira, p. 3133, 2006.

FOUCAULT, Michel. Em Defesa da Sociedade. $4^{a}$ tiragem. Tradução: Maria Ermantina Galvão. São Paulo: Martins Fontes, 2005.

IBGE - INSTITUTO BRASILEIRO DE GEOGRAFIA E ESTATÍSTICA. Conheça o Brasil-População: Trabalho e Rendimento. Rio de Janeiro, 2019. Disponível em: $<$ https://educa.ibge.gov.br/jovens/conheca-o-brasil/populacao/18314-trabalho-erendimento.html>. Acesso em: mai. 2019.

MARINHO, Ana; PINHEIRO, Hélder. O cordel no cotidiano escolar. São Paulo: Cortez, 2012.

MOREIRA, Ruy. Pensar e ser em Geografia. São Paulo: Contexto, 2007.

ROLIM, Marcos. A formação de jovens violentos: para uma etiologia da disponibilidade violenta, 2014. Tese (Doutorado em Sociologia) - Programa de Pós-graduação em 
Julia Gabriela Lessa de Queiroz Kelly Barradas Moreno

Leandro Vieira Cardoso da Silva
Geografia, Literatura e Arte, v.2, n.2, p. 15-30, jul./dez.2020 DOI: 10.11606/issn.2594-9632.geoliterart.2020.167885

Sociologia, 2014. . Disponível em: https://lume.ufrgs.br/handle/10183/102225 Acesso em: 18 jul. 2019.

ROSA, Daniel Pereira. São Gonçalo, Divisão do Trabalho na Metrópole e a Formação da Nova Periferia Metropolitana. Tamoios, ano IV, nº $1,2010$.

SILVA, Jailson de Souza; BARBOSA, Jorge Luiz. As favelas como territórios de reinvenção da cidade. In: BARBOSA, Jorge Luiz; DIAS, Caio Gonçalves (org.), Solos Culturais. Rio de Janeiro: Observatório de favelas, 2013, p. 29.

Recebido em 28/03/2020.

Aceito em 21/09/2020.

Publicado em 07/11/2020. 